\title{
Changes in plasma ionised calcium within 24 hours of trauma in patients infused with the calcium containing colloid Haemaccel during fluid resuscitation
}

\author{
P A Evans, W Madira, M S Riyatt, M Errington, S Heptinstall
}

Leicester Royal

Infirmary, Leicester, United Kingdom: Department of Accident and Emergency Medicine P A Evans

M S Riyatt

$M$ Errington

Department of Chemical Pathology W Madira

Department of Thrombosis and Haemostasis, University Hospital, Nottingham, United Kingdom

S Heptinstall

Correspondence to: Mr P A Evans, Accident and Emergency Department, Leicester Royal Infirmary, Leicester LE1 5WW.

Accepted for publication 12 November 1996

\begin{abstract}
Objective-To determine the changes in ionised plasma calcium levels over a 24 h period in patients sustaining blunt trauma injuries and infused with the calcium containing colloid Haemaccel ${ }^{\circledR}(6.25 \mathrm{mmol}$ litre $\mathrm{Ca}^{2+}$ ).

Methods-The study was carried out on 24 trauma patients who attended the accident and emergency (A\&E) department of the Leicester Royal Infirmary and required fluid resuscitation. Nineteen patients, with a mean injury severity score (ISS) of 14 (range 6 to 36), were given an infusion of Haemaccel; five patients in the control group with an ISS of 12 (range 6 to 19) were infused non-calcium-containing crystalloid. All types of fluids were recorded and serial plasma ionised calcium values were measured over a $24 \mathrm{~h}$ period. Results-The mean pre-Haemaccel ionised calcium value fell to $0.71 \mathrm{mmol} / \mathrm{litre}$ following trauma. The mean values (mmol/litre) obtained in patients infused with Haemaccel were measured at $2,4,8$, and $24 \mathrm{~h}$. In the Haemaccel group these values were 1.38 (SD 0.34), $1.40(0.44), 1.23$ (0.27), and $1.18(0.31)$ (at least $P<0.001 v$ baseline). The rise in calcium at $2 \mathrm{~h}$ was proportional to the volume of Haemaccel infused $(r=0.917 ; P<<0.001)$.

Conclusions-In all patients the plasma ionised calcium rose on infusion of Haemaccel and in a least one measurement $50 \%$ of patients developed hypercalcaemia ( $\mathrm{Ca}^{2+}<1.30 \mathrm{mmol} /$ litre). The clinical significance of this is at present unclear.

( Accid Emerg Med 1997;14:73-75)
\end{abstract}

Keywords: colloid; fluid replacement; ionised calcium; hypercalcaemia.

A fall in plasma ionised calcium is a recognised metabolic response to traumatic and nontraumatic muscle damage, ${ }^{1-4}$ and intracellular calcium mobilisation following injury has been demonstrated in vitro in human endothelial monolayers. ${ }^{5}$ Nevertheless the role of calcium supplementation during fluid resuscitation in trauma patients remains controversial, as reflected by the fact that certain intravenous fluids used contain calcium whereas others do not. Haemaccel ${ }^{\circledR}$ is a calcium containing colloid which has a standard ionised calcium content of $6.25 \mathrm{mmol} /$ litre and is commonly used, either alone or in combination with crystalloid, ${ }^{6}$ during resuscitation of shocked trauma patients in order to counteract the fall in plasma calcium in these patients.

It has, however, been observed that trauma patients who have received intravenous fluids containing calcium have significant prolongation of the bleeding time. ${ }^{7}$ This may be the result of inhibition of platelet aggregation by a direct effect of raised plasma calcium, as suggested previously. ${ }^{78}$

In the present study we have determined the level of plasma ionised calcium over a 24 hour period following resuscitation of trauma patients with Haemaccel.

\section{Methods}

Twenty four consecutive trauma patients admitted through Leicester Royal Infirmary accident and emergency (A\&E) department and requiring fluid resuscitation were included in the study. Nineteen patients (mean age 36 years, age range 19 to 77 ) with a mean injury severity score (ISS) of 14 (range 6 to 36) were given an infusion of Haemaccel, and a control group of five patients (mean age 42 years, age range 18 to 85 ) with an ISS of 12 (range 6 to 19) were given non-calcium-containing crystalloids; all agreed to supply blood samples for the duration of the study. The ISS was assessed as previously described. ${ }^{9}$ None of the patients were on any medication, or had any underlying illness known to affect plasma calcium concentrations. All patients were resuscitated following the advanced trauma life support guidelines. ${ }^{10}$ None of the patients had an arterial $\mathrm{pH}$ outside the normal range, as determined by blood gas analyser.

The fluid replacements were given in the usual way, with no modifications to patient management because of the study. The volumes and types of fluids infused and the infusion rates were recorded. Blood for the determination of ionised calcium was collected following the recommendations of Boink et al. ${ }^{11}$ Mixed venous blood (collected without tourniquet or stasis) or arterial blood samples for the immediate measurement of ionised calcium and $\mathrm{pH}$ (by an Instrumentation Laboratory 1640 BGE analyser) were collected into dry heparin tubes on admission and at $2,4,8$, and 24 hours. The $\mathrm{pH}$ adjusted calcium values 
Table 1 Effect of infusion of Haemaccel on plasma ionised calcium

\begin{tabular}{|c|c|c|c|c|c|}
\hline & \multirow{2}{*}{$\begin{array}{l}\text { Pre-Haemaccel } \\
\text { basal value }\end{array}$} & \multicolumn{4}{|c|}{ Time since trauma } \\
\hline & & $2 h$ & $4 h$ & $8 h$ & $24 h$ \\
\hline \multicolumn{6}{|l|}{ Haemaccel group } \\
\hline Mean ionised calcium (mmol/l) (SD) & $0.71(0.15)$ & $1.38(0.34)$ & $1.40(0.44)$ & $1.23(0.27)$ & $1.18(0.31)$ \\
\hline Range of ionised calcium ( $\mathrm{mmol} / \mathrm{l})$ & 0.49 to 0.90 & 0.91 to 2.02 & 0.97 to 1.94$)$ & 0.88 to 1.61 & 0.79 to 1.7 \\
\hline cf pre-Haemaccel value & NA & $P<0.001$ & $\mathrm{P}<0.001$ & $P<0.001$ & $P<0.001$ \\
\hline Mean volume Haemaccel infused per patient $(\mathrm{ml})$ & None & 1230 & 1500 & 1580 & 1640 \\
\hline Range Haemaccel volume infused & None & $500-2500$ & $500-3000$ & $500-3500$ & $500-3000$ \\
\hline \multicolumn{6}{|l|}{ Non-Haemaccel group } \\
\hline Mean ionised calcium (mmol/l) (SD) & $0.71(0.15)$ & $0.78(0.08)$ & $0.75(0.08)$ & $0.90(0.24)$ & $0.90(0.11)$ \\
\hline
\end{tabular}

The mean ionised calcium levels in five trauma patients who did not receive Haemaccel did not vary significantly from $0.71 \mathrm{mmol} /$ over the 24 hour period.

Reference range for ionised calcium in plasma is 1.18 to $1.30 \mathrm{mmol} / \mathrm{l}$.

were then determined (normal range 1.18 to $1.30 \mathrm{mmol} /$ litre. The results were compared using the Student $t$ test and regression analysis.

\section{Results}

Table 1 shows that the mean volume of Haemaccel infused per patient over the 24 hour study period was $1640 \mathrm{ml}(10.25 \mathrm{mmol}$ $\mathrm{Ca}^{2+}$ ), range 500 to $3500 \mathrm{ml}$ (3.13 to 21.88 mmol $\left.\mathrm{Ca}^{2+}\right)$. At all time intervals studied the mean ionised calcium values while receiving Haemaccel were highly significantly different from control values. The mean ionised calcium concentration ( $\mathrm{mmol} /$ litre) before infusion of Haemaccel was 0.71 (SD 0.15 , range 0.49 to 0.90 ), and at $2,4,8$, and 24 hours, during infusion of Haemaccel, the values were 1.38 (SD 0.34 , range 0.91 to 2.02$), 1.40(0.44,0.97$ to $1.91), 1.23(0.27,0.88$ to 1.61$)$, and 1.18 $(0.31,0.79$ to 1.87$)$, respectively (at least $P<$ 0.001 compared with the pre-Haemaccel value, table). The mean ionised calcium values ( 0.68 to $0.84 \mathrm{mmol} /$ litre) in five trauma patients who did not receive Haemaccel did not vary significantly from the basal value of $0.71 \mathrm{mmol} /$ litre over the 24 hour study period. In some patients infusion of Haemaccel caused significant hypercalcaemia, with ionised calcium levels as high as $2.07 \mathrm{mmol} /$ litre.

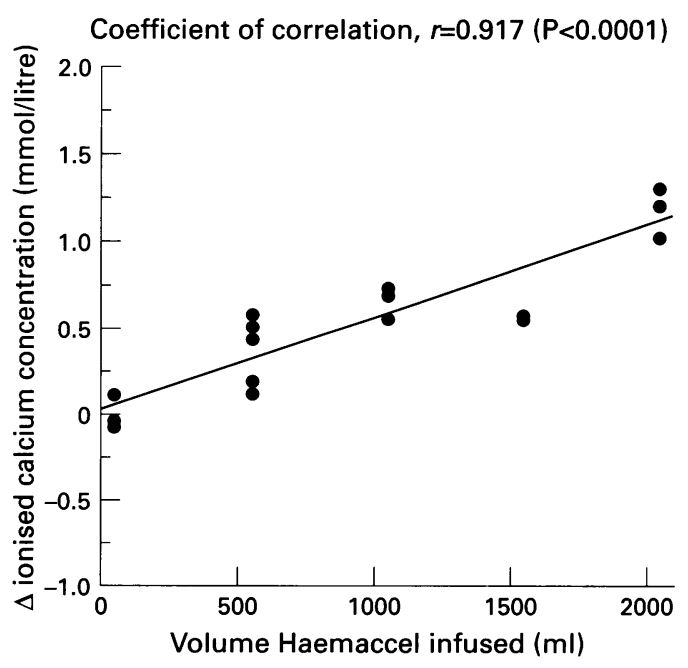

Figure 1 Ionised calcium was measured on admission in patients who required fluid resuscitation. The measurements were repeated two hours later following a rapid infusion with different volumes of Haemaccel at a calcium concentration of $6.25 \mathrm{mmol} / \mathrm{litre}$. The change in ionised calcium over the $2 \mathrm{~h}$ period was calculated.

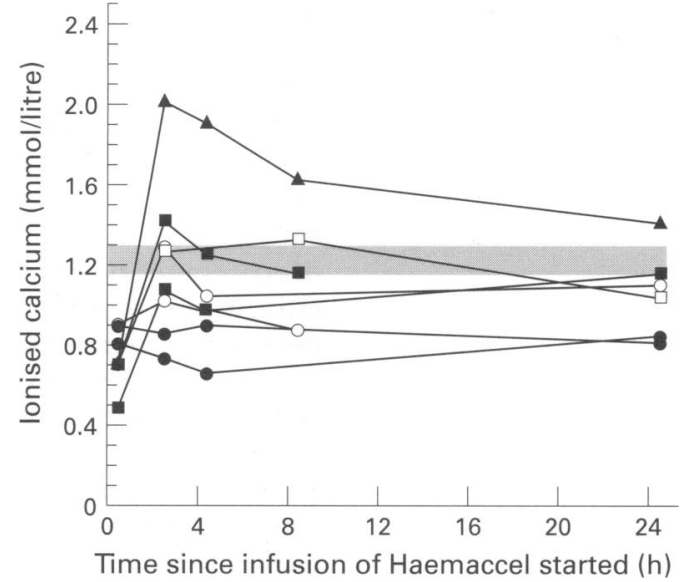

Figure 2 Ionised calcium was measured on admission in patients who required rapid fluid infusion during resuscitation. After the initial infusion no further Haemaccel was given and further ionised calcium measurements were repeated at $2,4,8$, and 24 hours. Volumes of Haemaccel (calcium concentration 6.25 mmol/litre) initially infused were: none $=\bullet-0 ; 500 \mathrm{ml}$; $1000 \mathrm{ml} \longrightarrow ; 1500 \mathrm{ml} \square \longrightarrow \square ; 2000 \mathrm{ml} \mathbf{\Delta}-\mathbf{\Delta}$. The shaded area represents the normal range.

Figure 1 shows that the rise in ionised calcium two hours after infusion of Haemaccel was directly proportional to the volume of calcium containing fluid infused $(r=0.917, \mathrm{P}<<$ $0.001)$. Infusion of 1 litre $\left(6.25 \mathrm{mmol} \mathrm{Ca}{ }^{2+}\right)$ and 2 litres $\left(12.5 \mathrm{mmol} \mathrm{Ca}^{2+}\right)$ of Haemaccel increased ionised calcium by about 0.5 and 1.0 $\mathrm{mmol} /$ litre respectively. Although the plasma ionised calcium concentrations rose rapidly in proportion to the volume of Haemaccel given, if the infusion rate was not maintained, the plasma calcium values tended to fall, usually to below the reference range, unless large volumes had been infused initially (fig 2 ).

\section{Discussion}

Our results confirmed previous observations ${ }^{12}$ that following trauma, plasma ionised calcium levels fall within 24 hours in those patients not receiving calcium containing fluids. The mean pre-Haemaccel infusion ionised calcium value was $0.71 \mathrm{mmol} /$ litre (normal range 1.18 to 1.30) and did not change significantly over a 24 hour study period in control patients who did not receive Haemaccel infusions. We have also shown that infusion of Haemaccel causes a marked rise in the concentration of plasma ionised calcium, sometimes significantly above physiological levels. There was a direct relation between the amount of Haemaccel infused and 
the increase in ionised calcium concentration. Hypercalcaemia $\left(\mathrm{Ca}^{2+}>1.30 \mathrm{mmol} /\right.$ litre $)$ was observed in at least one measurement in $50 \%$ of patients who were given Haemaccel infusions. In the trauma patients, following the infusion of Haemaccel the plasma ionised calcium concentration rose initially, but the levels then tended to fall, usually to below physiological levels, unless the infusion rate was maintained (fig 2), indicating a persistence of the normal response to trauma. Since this normal response is to lower the plasma ionised calcium, then raising the concentrations, especially above physiological values, may be deleterious for primary haemostatic mechanisms and cell function. In our study the calcium was raised, and quite markedly so, since the supranormal levels seen were superimposed on a low physiological level.

The high ionised calcium level may also reduce platelet aggregation by enhancing the rate of platelet disaggregation. There is an optimum concentration of extracellular plasma calcium required for platelet aggregation to be achieved. $^{8}$ When the level of calcium goes above this optimum level the extent of platelet aggregation is reduced by enhancing the rate of disaggregation, and this could be one of the factors that leads to an increase in bleeding time seen in the trauma patient.

The inhibitory effect of calcium on platelet aggregation in vitro ${ }^{8}$ and the prolongation of the bleeding time in traumatised patients following infusion of $\mathrm{Haemaccel}^{7}$ has, however, to be contrasted with the potentially detrimental effects of low plasma ionised calcium concentrations on myocardial function and the circulation. ${ }^{13}$ However, the shocked trauma patient has a greater tendency to hypoxic cellular damage due to hypoperfusion and hypostatic flow in vascular capillary beds, and infusing calcium containing fluids into these patients may increase the likelihood of influx of calcium into the cells. ${ }^{14}$ Previous investigators have suggested that this intracellular accumulation of calcium may be one of the reasons for a change from reversible to irreversible cell injury and death. ${ }^{15}$ The potential detrimental effects may therefore outweigh the benefits of the positive inotropic effects on the heart and the increase in vascular tone which may follow calcium infusion.

Further research is required to establish the optimal plasma calcium concentrations to be achieved following trauma.

We thank Mrs J Thomas for her secretarial help in constructing this manuscript.

1 Cumming $\mathrm{AD}$. The role of calcium in intravenous fluid therapy. Arch Emerg Med 1993;10:265-70.

2 Llach F, Felsenfeld AJ, Haussler MR. The pathophysiology of altered calcium metabolism in rhabdomyolysis-induced acute renal failure. J Med 1981;305:117-123.

3 Denis R, Lucas CE, Ledgerwood AM. The beneficial role of calcium supplementation during resuscitation from shock. calcium supplementation

4 Henderson SA, Graham HK, Mollan RAB. Serum and other calcium fractions in patients after severe musculoskeletal trauma. Clin Orthop Rel Res 1992;275:306-11.

5 Drumheller PD, Hubbell JA. Local modulation of intracellular calcium levels near a single-cell wound in human endothelium. Arterioscler Thromb 1991;11:125865.

6 Smith JAR, Norman JN. The fluids of choice for resuscitation of severe shock. Br J Surg 1982;69:702-5.

7 Evans PA, Garnett M, Boffard K, Kirkman E, Jacobson BF. Evaluation of the effect of colloid (Haemaccel) on the bleeding time in the trauma patient. J R Soc Med 1996;89: 101-4.

8 Heptinstall S. The use of chelating low exchange resin to evaluate the effects of the extracellular calcium concentration on adenosine diphosphate induced aggregation of human platelets. Thromb Haemost 1976;36:208-20.

9 Baker SP, O'Neil B, Haddan WJ, Long W. The injury severity score. A method for describing patients with multiple injuries and evaluating emergency care. J Trauma 1974;14: 187-96.

10 ATLS Course for Physicians. Students' manual. American College of Surgeons, 1998/1993.

11 Boink ABTJ, Buckley BM, Christiansen T, Covington AK, Maas AHJ, MullerPlathe O, et al. The recommendation on sampling, transport, and storage for the determination of sampling, transport, and storage for the determination of plasma, and plasma. F Int Fed Clin Chem 1992;4:147-52.

12 Hardy JRW, Conlan D, Haty S, Gregg PJ. Plasma ionised calcium and its relationship to parathyroid hormone after tibial fracture. J Bone Joint Surg Br 1993;75B:645-7.

13 Denis R, Lucas CE, Ledgerwood AM, Elliott L. The beneficial role of calcium supplementation during resuscitation from shock. J Trauma 1985;25:594-600.

14 Trunkey D, Holcroft J, Carpenter MA. Calcium flux during haemorrhage shock in baboons. J Trauma 1976;16:633-8.

15 White BC, Gadzinski DS, Hoehner PJ, Krome C, Hoehner $\mathrm{T}$, White JD, et al. Correction of canine cerebral cortical blood flow and vascular resistance after cardiac arrest using flunarizine, calcium antagonist. Ann Emerg Med 1982;22: 118. 